\title{
PRÁTICAS TRANSLÍNGUES NA FORMAÇÃO DE PROFESSORES DE INGLÊS: APROPRIAÇÃO E DEMOCRATIZAÇÃO DE REPERTÓRIOS LINGUÍSTICOS
}

\section{Translingual practices in English teachers' development: appropriation and democratization of linguistic repertoire}

\author{
Gabriela Claudino GRANDE \\ Universidade Federal de Mato Grosso do Sul \\ gabriela.grande@ufms.br \\ https://orcid.org/0000-0002-1593-2797
}

Ana Amélia Calazans da ROSA Universidade Federal do Triângulo Mineiro ana.calazans@uftm.edu.br https://orcid.org/0000-0001-9079-1958

Adolfo TANZI NETO

Universidade Federal do Rio de Janeiro adolfotanzi@letras.ufrj.br http://orcid.org/0000-0003-0347-7077

\begin{abstract}
RESUMO: Este artigo, apoiado nas discussões sobre translinguagem, perpassado por questões relativas à mobilidade, aos processos de hibridização e à fluidez (CANAGARAJAH, 2013) no ensinoaprendizagem de língua inglesa, analisou produções escritas de discentes de um curso de Letras-Português e Inglês de uma Universidade Federal no centro-oeste brasileiro. $\mathrm{O}$ objetivo foi descrever e refletir sobre quais das práticas de escrita que compõem as produções podem ser consideradas como práticas translíngues e como essas práticas refletem o posicionamento, as estratégias e as representações de si, marcando um processo de ensino-aprendizagem que abre possibilidades de um uso mais plural e orientado para uma concepção de língua democrática como recurso para produção de significados (BLOMMAERT, 2010). A translinguagem, dentro do contexto analisado, dá suporte ao uso de estratégias e ampara as construções semióticas identitárias dos professores em formação. Os resultados também apontam para o desenvolvimento e a expansão de repertórios linguísticos em produções escritas dentro das disciplinas pesquisadas. Sendo assim, o presente trabalho espera dar orientação a professores e educadores de forma a identificar não apenas formas de ampliação de repertórios linguísticos, mas também para que mais cursos de graduação possam refletir sobre
\end{abstract}


práticas translíngues para o desenvolvimento, ampliação e democratização linguística dos graduandos.

PALAVRAS-CHAVE: Translinguagem; Formação de professores; Repertório linguístico.

\begin{abstract}
This paper is based on discussions about translanguaging, pervaded by concerns related to mobility, the processes of hybridization and fluidity (CANAGARAJAH, 2013) in the teaching-learning processes of English language. We analyzed undergraduates' written productions of an English and Portuguese Language undergraduate course at a Federal University in the Brazilian Midwest. We aimed at describing and reflecting upon which writing practices we could consider as translanguaging practices, and how these practices could reflect the social positioning, strategies and representations of oneself in relation to a learning-teaching process which considers a more plural language usage, towards a concept of democratic language as a resource for meaning making (BLOMMAERT, 2010). Translanguaging, within the analyzed context, supports the use of strategies and supports semiotic identity constructions of teachers in training. The results indicated the development and expansion of linguistic repertoires in the additional language written productions from the studied courses. Therefore, the present work sought to contribute to a growing area, hoping to provide guidance to teachers and educators in order to identify not only ways to expand linguistic repertoires, but also so that more undergraduate majors could reflect on translanguaging practices for undergraduates' linguistic development and expansion.
\end{abstract}

KEYWORDS: Translanguaging; Teachers' development; Linguistic repertoire.

\title{
INTRODUÇÃO
}

Em tempos de globalização e da forte onda neoliberal que assola o mundo, para pensar a formação crítica do cidadão é preciso repensar conceitos outrora tidos como estáveis, sobretudo aqueles referentes ao ensino-aprendizagem de língua enquanto sistema e estruturas. Conhecer ou desconhecer determinados conteúdos escolares, incluindo uma determinada língua e seus repertórios mais valorizados, não é uma escolha livre de ideologia (neutra). Os saberes tidos como básicos, clássicos e/ou naturalizados, muitas vezes são vistos como descontinuados de sua produção histórica e, por isso mesmo, dados como verdades absolutas, apagando o espaço de outros saberes, outras narrativas, outras línguas. 
As línguas e os repertórios escolhidos como prioritários pelas diversas políticas linguísticas para serem objetos de ensino e/ou de poder são, necessariamente, escolhidos sob óticas ideológicas dominantes. Em concordância com Lopes e Silva (2018), acreditamos também que tratar de línguas e de seu ensino é transitar em um território de disputa. Uma língua não é simplesmente "um fato da natureza" (p. 700), é sim um território de luta política e este artigo procura, assim como Lopes e Silva (2018) fizeram, deslocar a concepção de ensino de língua do campo da natureza linguística para o campo político dos diferentes usos de uma língua em expansão global, como é o caso da língua inglesa.

Para Figueiredo (2018), devido às mudanças da nossa relação com as localidades, acontecimentos locais e forças globais, estudos sobre o ensino-aprendizagem de línguas tornam-se essenciais para entendermos os entrelaces entre língua, cultura, economia, política e sociedade num mundo cada vez mais interconectado. Para o autor, as escolhas linguísticas (variedade instrucionais, variedades de usos e modelos disponíveis para os estudantes) de um professor estão diretamente relacionadas a diferentes "ideologias de domínio, internacionalização e/ou conhecimento em nosso atual contexto de globalização" (FIGUEIREDO, 2018, p. 32).

A concepção de que línguas socialmente constituídas seriam sistemas fechados e o mito do monolíngue (MAHER, 2013), apesar de amplamente difundidos, não se sustentam na sociedade atual, especialmente quando sabemos, segundo dados do Atlas of the World's Languages in Danger (2010), que há mais de 6.000 (seis mil) línguas faladas no mundo, número expressivamente maior do que o número de países ${ }^{1}$. Sendo assim, é seguro dizer que grande parte dos países conta com múltiplas línguas e que a ideia de pensar língua apenas pelo viés territorial é reducionista.

O multilinguismo é, inegavelmente, uma realidade no Brasil e, segundo Maher (2013), nosso país conta com mais de 220 línguas maternas, das quais a maioria são indígenas; sem mencionar a grande mobilidade e os movimentos migratórios que têm trazido falantes de outras línguas e práticas sociais superdiversas para o território brasileiro. Ademais, vale ressaltar a grande influência da língua inglesa, atualmente

\footnotetext{
${ }^{1}$ Atualmente, a ONU (Organização das Nações Unidas) reconhece a existência de 193 países-membros. Disponível em: <https://nacoesunidas.org/conheca/paises-membros/> Acesso em: 10 jan. 2020.
} 
"escolhida" como a única língua adicional obrigatória para a educação básica brasileira conforme a nova Base Nacional Comum Curricular - BNCC (BRASIL, 2017), enquanto língua hegemônica, simbólica para ascensão e inclusão social (RAJAGOPALAN, 2005).

As transformações para esses novos entendimentos acerca da linguagem não são isoladas, a sociedade e as culturas também estão em constante movimento e entrecruzamentos propiciados pelas porosidades de bordas pouco definidas (SIGNORINI, 2012) que surgem a medida que espaços desterritorializados, tal qual os espaços de fluxos (CASTELLS, 2007), com o ciberespaço, ganham relevância nas práticas sociais.

No pano de fundo sócio-histórico-cultural que perpassa o presente artigo, consideramos relevante a forma como a sociedade tem promovido princípios de privatização e a mercantilização de habilidades e recursos naturais, percebida pela ascensão dos discursos neoliberais. Tais movimentos causam grande preocupação à educação, e em particular à educação bilíngue, “já que o bilinguismo se torna valioso não por sua capacidade de aumentar o acesso de seus falantes e sustentar línguas minoritárias [preconizado pela translinguagem], mas por seu papel de criar trabalhadores capazes numa economia globalizada" (POZA, 2017, p. 102).

Embora a translinguagem sempre tenha existido, estudos na Linguística Aplicada, políticas linguísticas e o interesse de pesquisadores têm se intensificado apenas na última década. As políticas linguísticas aliadas aos movimentos migratórios e à internacionalização do mercado e de ambientes acadêmicos, por exemplo, dão força à translinguagem, particularmente no ensino de língua inglesa, sobretudo por motivos econômicos.

Adicionalmente a "simples aquisição" de uma nova língua, a translinguagem dá abertura para que questões de raça, gênero, identidade, classe, sexualidade, cultura, etnia, dentre outras, possam emergir (GARCÍA; WEI, 2014), justamente porque reconhece "que os recursos linguísticos são desigualmente distribuídos e que a luta por eles é política" (LOPES; SILVA, 2018, p. 700). Essas questões vão ao encontro de abordagens educacionais ligadas aos Letramentos Críticos (doravante, LC) e à Pedagogia dos Multiletramentos (THE NEW LONDON GROUP, 1996) ${ }^{3}$, questionando relações de poder

\footnotetext{
${ }^{2}$ A escolha pelo monolinguísmo foi uma imposição do governo Temer quando, em 2017 , lança a nova BNCC.

${ }^{3}$ Devido ao escopo deste trabalho, não aprofundaremos as discussões teóricas, já amplamente debatidas na literatura, sobre Letramentos Críticos e Multiletramentos, mas entendemos que ambas as áreas estabelecem
} 
constituídas nos campos das linguagens e das culturas e construindo sentidos que sejam relevantes à vida dos discentes. Assim, além das habilidades linguísticas através da materialidade da língua adicional ${ }^{4}$, os LC e os Multiletramentos contribuem para a formação de cidadãos críticos que lutam por uma sociedade menos desigual (MONTE MÓR, 2013).

Frente ao que foi exposto, o presente artigo discute como o conceito e práticas translíngues no ensino superior podem contribuir para expansão de repertórios linguísticos de professores de língua inglesa em formação. Apoiados nas discussões de práticas de linguagens da perspectiva dos repertórios dos falantes e não apenas pelas descrições normativas de uso da língua (GARCÍA, 2017), e perpassados por questões relativas à mobilidade, aos processos de hibridização e à fluidez (CANAGARAJAH, 2013), tão caros à era da globalização, analisamos produções escritas de discentes de um curso de Letras de uma universidade federal no centro-oeste brasileiro, com o objetivo de refletir sobre que práticas de escrita encontradas nessas produções podemos considerar como práticas evidentemente translíngues e como essas práticas translíngues refletem o posicionamento/ estratégias/representações dos com relação à apropriação/expansão/democratização do repertório linguístico dos aprendizes.

\section{TRANSLINGUAGEM: UM ATO DEMOCRÁtico PARA EDUCAÇÃo LINGUÍSTICA}

Os fenômenos da mobilidade, em expansão global, aliados a sociedade em rede (CASTELLS, 2007) e à transculturalidade (PENNYCOOK, 2007) fazem com que novas formações sociais surjam em nossa sociedade. Tais formações resultam em práticas sociais e comunidades de práticas (WENGER, 1998) cada vez mais complexas, híbridas e fluidas, nas quais a(s) língua(s), muitas vezes desterritorializadas, surgem como elemento pivotal $^{5}$ para interação, fazendo da translinguagem a norma, e não a exceção.

uma relação importante e direta com as perspectivas teóricas sobre Translinguagem apresentadas neste artigo.

${ }^{4}$ Preferimos o termo língua adicional, em oposição ao consagrado "língua estrangeira", pois implica na concepção de que há igualdade de condições entre falantes, sejam nativos ou não, uma vez que o falante utilizará a língua para se comunicar no contexto no qual está inserido, não sendo assim excluído por ser um “estrangeiro". A língua adicional também evoca a reflexão em relação ao que é a língua, "de quem ela é e de quem pode ser, a que ela serve e o que cada um tem a ver com ela" (SCHLATTER; GARCEZ, 2009).

${ }^{5}$ Após várias leituras no acabamento deste artigo percebemos que algumas escolhas lexicais para produção de nossos significados foram advindas de práticas translíngues (Espanhol, Inglês), ou seja, da nossa 
Ainda que o termo translinguagem tenha surgido na década de 80, é apenas a partir de 2011 que pesquisas sobre práticas translíngues têm ganhado maior visibilidade na literatura (POZA, 2017). Independentemente de ser considerada uma pedagogia ou uma teoria linguística, pesquisadores com interesse na área concordam que a translinguagem tem o objetivo de romper com as hierarquias entre e dentro das línguas nomeadas ${ }^{6}$, propiciando voz às minorias e abrindo espaços para discussões acerca de processos políticos e poder (FLORES, 2014).

Neste sentido, e em consonância com o argumento de Makoni e Meinhof (2006), entendemos que ver a língua enquanto um conceito exclusivamente ligado às noções de governos e estados-nação é muito diferente de conceber a língua enquanto experiências dos usuários, práticas linguísticas "de baixo pra cima" que tentam captar os usos locais da língua. Segundo a pesquisa dos autores sobre os conceitos de língua na África, descrições linguísticas e ensino-aprendizagem de línguas pautados em pressupostos que atendem a governos e territórios (perspectivas centrípetas) são, quase sempre, insensíveis e até coercitivas em relação às práticas locais de uso e de aprendizagem. Por outro lado, as descrições das práticas linguísticas locais são estranhas e muitas vezes negadas (soam como não-práticas ou como práticas equivocadas) aos olhos das agências de letramentos ligadas aos estados-nação.

Portanto, citando Makoni e Meinhof (2006, p. 210), “[o]interesse na língua é importante em uma etnolinguística aplicada que considere seriamente os vários modos como a linguagem é compreendida". Nesse viés, no caso dos estudos sobre usos de outra língua (língua adicional), as diversas práticas linguísticas dos falantes não-legitimados como "nativos ideais" da língua adicional são tidas como "estranhas", soando como “práticas equivocadas", para usar os termos de Makoni e Meinhof (2006). Isso significa dizer que, até em contextos bilíngues, o que tem valor sócio-historicamente é que o usuário domine separadamente duas línguas em suas variedades padrão e pautadas na gramática e na pronúncia de um suposto falante ideal.

São justamente essas práticas linguísticas "não-legitimadas”, entendidas aqui como

apropriação de repertório linguístico super diverso. Observamos que mesmo após a avaliação às cegas, os recursos translíngues não se revelaram estranhos aos leitores. Sendo assim, entendemos que esse recurso translíngue é compreendido pela comunidade para o qual esse trabalho se destina. Mesmo não sendo termos dicionarizados na língua portuguesa, optamos por deixá-los como reflexo da teoria discutida nesta pesquisa. ${ }^{6}$ Línguas nomeadas: normas externas socialmente construídas que são "impostas" aos falantes (TURNER; LIN, 2017, p. 425). 
práticas translíngues, que estão para além da alternância de códigos linguísticos (codeswitching). Dessa forma, o uso de complexos repertórios linguísticos trazidos pelos alunos entram em jogo na sala de aula numa dimensão pedagógica híbrida do uso da língua alinhada a propósitos sociais e políticos, nas mais diversas situações sociolinguísticas. É preciso, portanto, lidar com diversas línguas que coexistem em espaços não delimitados por fronteiras físicas ou mentais, mas sim espaços que são ampliados, (re)criados e (trans)formados pelos usuários e suas práticas (ANWARUDDIN, 2018).

Assim, e desafiando pressupostos monolíngues, a perspectiva da translinguagem não entende os sistemas linguísticos enquanto entidades separadas. Ao contrário, compreendemos que o sujeito não "liga e/ou desliga" uma língua de cada vez, como se suas práticas e suas representações de mundo fossem completamente independentes. $\mathrm{O}$ sujeito translíngue transita por seu repertório linguístico acessando e utilizando os recursos disponíveis para atribuir significado e moldar experiências comunicativas através do uso de línguas que coexistem em sua mente dentro de um sistema único e integrado (GARCÍA; WEI, 2014). Nesse sentido, as práticas translíngues envolvem falantes e seus repertórios linguísticos que podem contemplar uma, duas ou mais línguas, bem como recursos semióticos diversos ${ }^{7}$ (CANAGARAJAH, 2013). Nesse sentido, recursos semióticos que podem transformar as estruturas sociais, questionar relações de poder e controle e abrir espaços para práticas mais democráticas de aprendizagem.

É importante ressaltar que a noção de repertório linguístico, revisitada por Busch (2012), toma distanciamento das questões unicamente ligadas a estrutura, sistema e regularidade, para o reconhecimento da fluidez e da criatividade das práticas translíngues. Essa noção está intrinsicamente ligada à superdiversidade (VERTOVEC, 2007) caracterizada pelos processos migratórios e pelas relações sociais e econômicas translocais, uma vez que contempla práticas de networking socialmente complexas.Por sua vez, destaca como o repertório linguístico pode apontar não apenas os recursos que o indivíduo pode ter, como também aqueles recursos ausentes, mas desejáveis, das diferentes interações sociais vivenciadas no contexto globalizado, ou seja, diferentes encontros multissemióticos com as línguas que levam a "diferentes níveis de conhecimento/reconhecimento linguístico travestidos em repertórios linguísticos

\footnotetext{
${ }^{7}$ Tais recursos compreendem tanto diversas modalidades de comunicação, sistemas simbólicos (ícones etc.), como também os diversos contextos de comunicação social e material.
} 
superdiversos" (TANZI NETO; OLIVEIRA, 2018, p. 46).

Quando há potencialidades desejáveis, a linguagem frequentemente age como andaime que ampara discentes bilíngues para a aprendizagem de uma segunda língua (LEWIS; JONES; BAKER, 2012). A(s) língua(s) nomeada(s) sendo aprendida(s) carrega(m) ideais hegemônicos, como é o caso da língua inglesa; no entanto, faz parte do papel do professor crítico, que procura atuar na perspectiva da translinguagem na língua adicional, utilizar a oportunidade de educação linguística para reflexão e acolhimento dos diferentes repertórios linguísticos trazidos em sala para uma negociação democrática e de conscientização na formação de cidadãos socialmente conscientes dos discursos de poder. $\mathrm{O}$ aspecto crítico das perspectivas educacionais citadas também "coloca ambos professores e alunos em uma visão mais horizontal de distribuição de poder e da validade da verdade em direção a construção do conhecimento mais ampla e plural" (ROCHA; MACIEL; MORGAN, 2017, p. 3), validando a diversidade epistemológica ao promover diálogos entre saberes que historicamente têm sido negligenciados pela cultura grafocêntrica escolar.

O respeito a formas plurais de construção de conhecimento também faz parte dos princípios da translinguagem, que valoriza e incentiva o uso de variedades locais como forma de expressão de identidades, conforme Canagarajah (2013), a seguir:

não há variedade [de língua] estável que exista em comunicação em zonas de contato. Esse tipo de comunicação funciona porque os falantes estão preparados para seguir estratégias de co-construção de normas locais, e alcançar inteligibilidade através de (e não apesar de) suas identidades bem como variedades locais (CANAGARAJAH, 2013, p. $68)$.

A criação de espaços democráticos para esse tipo de construção do conhecimento depende do professor, participação/colaboração discente e da abertura institucional. $O$ contexto de educacional precisa ser propício para que discentes possam interagir e usar a linguagem de forma criativa e crítica, problematizando expressões de identidades e quebrando barreiras dicotômicas de línguas. Em outras palavras, por meio de práticas translíngues, a criação de um terceiro espaço (third space) em sala de aula abre possibilidades emancipatórias para conscientização democrática.

Nessa mesma linha de raciocínio, o "Letramento Crítico [também] parte da 
premissa de que a linguagem tem natureza política” (MONTE MÓR, 2013, p. 42). O LC “combina os estudos de Freire, a teoria crítica social e o pós-estruturalismo [...] para o entendimento de textos como construções ideológicas" (CERVETTI; PARDALES; DAMICO, 2011, p. 5) sendo um instrumento de justiça, igualdade e liberdade, associado à ideia de "emancipação" do sujeito para que ele possa, através da linguagem, atuar nas diferentes práticas sociais, de modo a posicionar-se enquanto sujeito crítico e provocar mudanças se assim desejar (SANTOS; IFA, 2013).

Adicionalmente ao que é proposto pelo LC e pela translinguagem, os multiletramentos colocam a pluralidade linguística e a diversidade cultural da contemporaneidade enquanto questões principais para o ensino. "O que seria apropriado para todos, mulheres, indígenas, imigrantes, entre outros, no contexto de fatores de diversidades, local e conectividade global, cada vez mais críticos?" (NEW LONDON GROUP, 2006 [1996], p. 10).

The New London Group ${ }^{8}$ buscava a construção de espaços para aprendizagem nos quais práticas de letramentos (mais ou menos valorizadas; grafocêntricas ou não) e eventos da vida cotidiana, da arte não-canônica, da vida profissional e cidadã, pudessem compor os letramentos e as práticas de sala de aula. Para Kalantzis e Cope (2010), a escola deveria desenvolver nos alunos formas de expressão de identidades diversas e condizentes com diferentes modos de vida, valorizando o respeito a culturas e linguagens híbridas (ROJO; MOURA, 2012) e criando oportunidades para que os aprendizes possam se engajar em práticas colaborativas e de respeito mútuo.

Por fim, entendemos que tais perspectivas educacionais podem ampliar a forma que temos trabalhado a educação bilíngue, não só pelo aprendizado de mais um sistema linguístico, mas pela luta para ter acesso a mais de uma língua. Em oposição a metodologias tradicionais e puristas, advogamos pela educação linguística que abra espaço a posicionamentos, estratégias e representações políticas, sociais e culturais no processo de apropriação e expansão do repertório linguístico de cada sujeito, dando suporte ao uso de estratégias translíngues e amparando construções semióticas identitárias mais democráticas.

\footnotetext{
${ }^{8}$ Em 1994, um grupo de pesquisadores e estudiosos resolveu reunir-se em Nova Londres (USA) para a discussão dos letramentos e seus significados. Segundo Rojo (2010), esse grupo encontrou no prefixo 'multi' a solução para o impasse. O termo 'multi' se referia a duas dimensões dos letramentos - multicultural e multimodal.
} 
O cenário nacional de ensino e aprendizagem de línguas adicionais tem reunido evidências substanciais sobre abordagens educacionais. No entanto, no que tange à translinguagem, as discussões ainda são muito recentes e acreditamos que mais pesquisas são necessárias. Ancorados por essa necessidade, esperamos que este trabalho possa contribuir na expectativa de que possamos dar orientação aos professores e educadores sobre perspectivas democráticas educacionais críticas para educação linguística.

\section{METODOLOGIA}

Pesquisas do campo da Linguística Aplicada na área de educação linguística vêm, há algum tempo, repensando o ensino e aprendizagem de línguas adicionais e procurando entender melhor os processos sócio-cognitivos do sujeito bilíngue. Pautados em estudos recentes na área da translinguagem, nosso trabalho surgiu com os seguintes questionamentos:

\footnotetext{
- Dentre os excertos selecionados em avaliações, quais são as práticas de escrita de graduandos em Letras - Português e Inglês - que podemos considerar como práticas evidentemente translíngues?

- Como essas práticas translíngues refletem os(as) posicionamentos/ estratégias/representações dos sujeitos com relação à apropriação/ expansão/democratização dos repertórios linguísticos dos aprendizes?
}

Para responder tais questionamentos, analisamos produções escritas de discentes de um curso de Letras - Português e Inglês de uma Universidade Federal no centro-oeste brasileiro entre 2017 e 2018. Por meio delas, pudemos identificar variadas práticas translíngues e analisar seu papel nos usos da língua inglesa nos textos analisados. A seguir, trazemos uma breve contextualização do corpus estudado e dos sujeitos que colaboraram com essa investigação. Na sequência, entramos na discussão do papel do corpus analisado nos processos que estamos entendendo como ensino-aprendizagem pautado em perspectivas translíngues, nas quais as línguas materna e adicional produzem novas práticas (GARCÍA; WEI, 2014), apropriações, expansões e democratização dos repertórios linguísticos. 


\section{CONTEXTUALIZAÇÃO DA PESQUISA}

Enquanto jovens pesquisadores e professores brasileiros de cursos de Letras Português e Inglês em três diferentes estados (Mato Grosso do Sul, Minas Gerais e Rio de Janeiro), nossa prática docente, que envolve ensino, pesquisa e extensão, nos coloca diante de um impasse: o baixo nível de proficiência em língua inglesa de grande parte dos discentes que ingressam no ensino superior. O impasse deve-se, sobretudo, ao fato de nossas licenciaturas incluírem a língua inglesa como uma das habilitações atribuídas ao discente quando concluem a graduação e ao fato de que a língua inglesa, independentemente de sua (problemática) hegemonia, ser utilizada incambiavelmente como língua para internacionalização de ambientes acadêmicos.

Isso posto, ao desenvolver um projeto de pesquisa ${ }^{9}$ sobre a translinguagem em uma Universidade no centro-oeste do Brasil, sentimos a necessidade de investigar de que forma as práticas translíngues poderiam ou não desenvolver as potencialidades linguísticas de aprendizagem da língua nomeada (inglês) durante duas disciplinas de formação de professores em um curso de Letras na referida Universidade. De tal modo, pautados por nossas curiosidades de pesquisadores aliadas às nossas necessidades enquanto educadores, decidimos, portanto, verificar de que forma, e em que medida, a translinguagem, particularmente em avaliações escritas dos graduandos, poderia colaborar para expansão do(s) repertório(s) linguístico(s) e como essas práticas translíngues refletem os(as) posicionamentos/estratégias/representações dos sujeitos com relação à apropriação/ expansão/democratização do seus repertórios linguísticos.

A fim de investigar tais inquietações, convidamos uma professora e 18 discentes de um curso de Letras Habilitação Português e Inglês da Universidade mencionada anteriormente para participarem do presente estudo. Todos os participantes assinaram, de forma voluntária, um Termo de Consentimento Livre e Esclarecido, no qual os pesquisadores explicavam o intuito da pesquisa.

Durante o primeiro semestre de 2017, mais especificamente no mês de junho, a professora Gisele ${ }^{10}$ aplicou provas escritas formais para o terceiro semestre do curso

\footnotetext{
${ }^{9}$ O projeto de pesquisa ao qual fazemos referência é "O papel da multimodalidade e da internet no ensino de línguas adicionais".

${ }^{10}$ Os nomes utilizados são fictícios para preservação do anonimato dos participantes da pesquisa conforme o Termo de Consentimento Livre e Esclarecido assinado pelos participantes e colaboradores.
} 
dentro da disciplina de Língua Inglesa III. A turma contava com 16 discentes. Durante o segundo semestre de 2018, mais especificamente em outubro, novos dados foram gerados, produções escritas de avaliações formais na mesma turma cujos primeiros dados haviam sido gerados em 2017, desta vez, no entanto, dentro da disciplina de Língua Inglesa VI. A turma contava com 12 discentes, dos quais 10 estavam presentes em 2017.

Além das análises das produções escritas per se, entrevistas foram conduzidas com os discentes e a docente, com a ajuda de uma aluna de Iniciação Científica, nas quais esclarecemos dúvidas com relação aos registros e também com relação às perspectivas educacionais que perpassam as práticas pedagógicas da docente Gisele.

De acordo com Gisele, os LC e a noção de translinguagem servem como referencial em suas preparações de aulas e avaliações escritas. Essa afirmação pode ser percebida ao elencarmos, conforme abaixo, os temas, em sua maioria transversais, utilizados nos enunciados propostos para questões dissertativas, trazidas nos exemplos das análises dos recortes que foram feitos das provas.São eles:

1. 2017 - Questão D - Por definição, a democracia não se limita à vontade da maioria; é também sobre a proteção dos direitos individuais e minoritários. No entanto, estamos vivendo tempos em que países ditos democráticos, como os EUA e o nosso, excluem mulheres, negros, homossexuais e indígenas do seu gabinete. Além disso, podemos observar alguns projetos de lei que favorecem algum tipo de "limpeza" na população (a reforma da imigração de Donald Trump e as propostas de cura gay no Brasil, por exemplo). Como você se sente sobre tudo isso? Crie um texto opinativo nas linhas fornecidas.

2. 2018 - Questão A - O cartum acima critica o presidente dos Estados Unidos da América, Donald Trump. Os "verdadeiros americanos" referidos ganham voz, enquanto pessoas de grupos minoritários parecem perder a voz no governo atual. Ultimamente, um dos candidatos a presidência tem sido comparado a ele? Você sabe quem é esse candidato? Como eles são comparáveis?

3. 2018 - Questão C - Como você descreveria um bom candidato à presidência?

Com base na contextualização apresentada na presente seção, seguimos para as análises das práticas translíngues encontradas à luz da literatura discutida neste trabalho. 


\section{RESULTADOS E DISCUSSÃO}

A justaposição constante de línguas e repertórios em contextos de sala de aula nos encoraja, na tentativa de melhor entender tais fenômenos sociais, a abarcar práticas transculturais translíngues para salas de aula de língua adicional, sobretudo, no ensino superior. Levando-se em conta a complexidade das relações e dos contextos de produções de linguagem e sentido, analisamos alguns recursos e estratégias utilizados pelos discentes nas produções escritas. O recorte aqui proposto é representativo de diversos exemplos encontrados. Apresentamos quatro exemplos que, a nosso ver, ilustram posicionamentos, estratégias comunicativas e representações identitárias dos discentes ${ }^{11}$.

No primeiro exemplo (cf. Figura 1), retirado da prova escrita aplicada em 2017, Evandro responde à questão $\mathrm{D}$, que versa sobre a exclusão governamental de grupos minoritários e pede ao discente que se posicione sobre o assunto. Percebemos, ao ler a resposta de Evandro, que as orações apresentam, do ponto de vista da língua padrão, desvios morfossintáticos diversos. Por exemplo, quando Evandro usa "how" ao invés de "as" para se referir à palavra "como" no sentido comparativo. Ou ainda, quando o aluno utiliza a regra do português - acrescentar o $\mathrm{S}$ - para colocar a palavra "country" no plural. Além disso, o discente utiliza palavras em português quando não dispõe de outro recurso e transpõe traduções "literais" do português - "has" ao invés de "thereis", já que no Brasil o verbo "ter" é comumente utilizado no sentido de existir/haver em contextos de uso coloquial da língua.

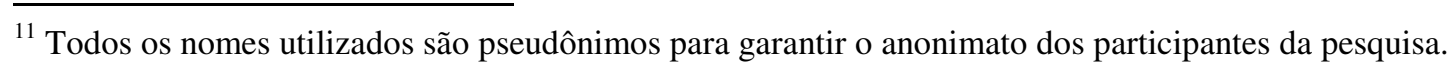


Figura 1. Evandro 2017. Exemplo 1 de uso da translinguagem para "hibridização morfossintática"12

D) By definition, democracy is not merely about majority will; it's also abcut the protection. of individual and minority rights. Yet, we are living times when so-claimed democratic countries, such as the USA and our own, exclude women, black, homosexual and indigenous people from their Cabinet. In addition to that, we can notice some plans that favor some kind of "cleansing" in the population (the immigration reform by Donald Trump, and the gay cure proposals in Brazil, for example). How do you feel about all that? Write your opinion in the lines provided. ( 2.0 points) ip

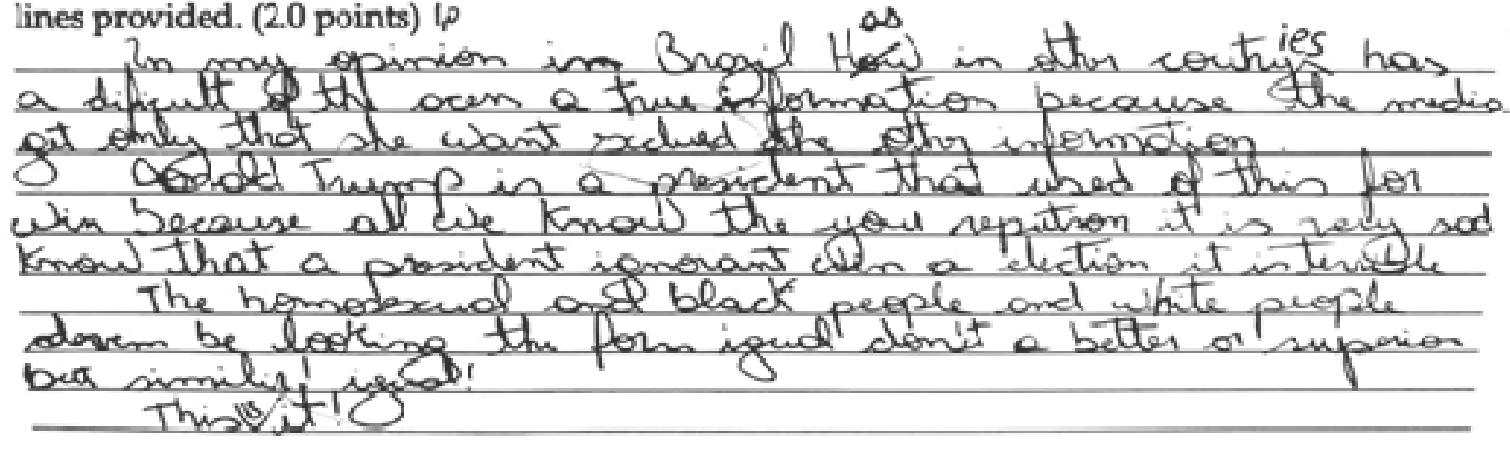

Fonte: Dados dos pesquisadores.

Tais estratégias de comunicação são consideradas desvios segundo a norma padrão da língua inglesa, pois ferem regras de processos morfológicos e sintáticos, além de configurarem usos considerados "não existentes" (como é o caso do "has" no lugar de "there is"). Nenhum desses casos, no entanto,configura problemas para inteligibilidade da professora, que, por sua vez, fez algumas poucas marcações no texto de Evandro. Curiosos, conversamos com a docente, Gisele, sobre sua forma de avaliação dos excertos:

"Eu me importo com proficiência linguística desses alunos, afinal serão professores, e nós trabalhamos forma e estrutura também. Mas estou mais interessada em saber como os discentes constroem discursos e articulam ideias de maneira coerente e crítica. Eu gosto de saber como os alunos lêem o mundo e a si mesmos e isso me importa muito mais do que erros gramaticais, esses [os erros] são mais fáceis de serem apreendidos do que o desenvolvimento de um pensar emancipador". (Entrevista Gisele, outubro 2017).

O que está em jogo para Gisele, portanto, é a forma de expressão e articulação de ideias do discente, bem como o uso da língua sendo ensinada na disciplina, e a forma crítica como a leitura do questionamento é feito, o que vai ao encontro dos princípios dos 
Letramentos Críticos, por exemplo. Nesse sentido, a professora Gisele busca acolher as práticas linguísticas locais (MAKONI; MEINHOF, 2006), ou das estruturas da língua minoritária, neste caso o português, não como prática equivocada, mas como processo translíngue, considerando os vários modos como a língua pode ser compreendida e utilizada pelos envolvidos no grupo em questão.

O segundo exemplo (cf. Figura 2), apresentado na sequência,traz a resposta da aluna Mariana referente à seguinte pergunta: Como você descreveria um bom candidato à presidência? É relevante ressaltar que as perguntas que são feitas por Gisele propiciam formas subjetivas de expressão e, por conseguinte, os discentes podem se expressar, em um espaço seguro (terceiro espaço proposto pela translinguagem), para articularem seus pensamentos de maneira honesta e democrática. Em 2018, ano em que a questão foi feita, o Brasil passava por eleições presidenciais tensas e polarizadas, sobretudo diante das fortes ondas conservadoras que têm surgido pelo mundo. Nesse sentido, a questão propicia ao alunado que reflita sobre que tipo de pessoa seria ideal para governar o país em que vivem.

Mariana (cf. Figura 2) integra o inglês e o português de forma fluida, como proposto com Canagarajah (2013), quando usa a expressão: “a good president candidate will be a kind of a person who care the minority who propoused things in prol of all people”. Ou seja, quando García (2014) afirma que línguas nomeadas não são sistemas separados e que agem de forma integrada nas construções de significados em nossos cérebros, podemos ver no excerto acima que essa máxima se aplica a aluna Mariana. Há vários indícios de construções sintáticas e lexicais na língua materna, o português, ainda que o texto esteja, inegavelmente, em língua inglesa.

$\overline{{ }^{12} \text { Parte das denominações dos exemplos de translinguagem mencionados foram adaptadas e inspiradas por }}$ 
Figura 2. Mariana 2018. Exemplo 2 de uso da translinguagem para "Integração Inglês e Português"

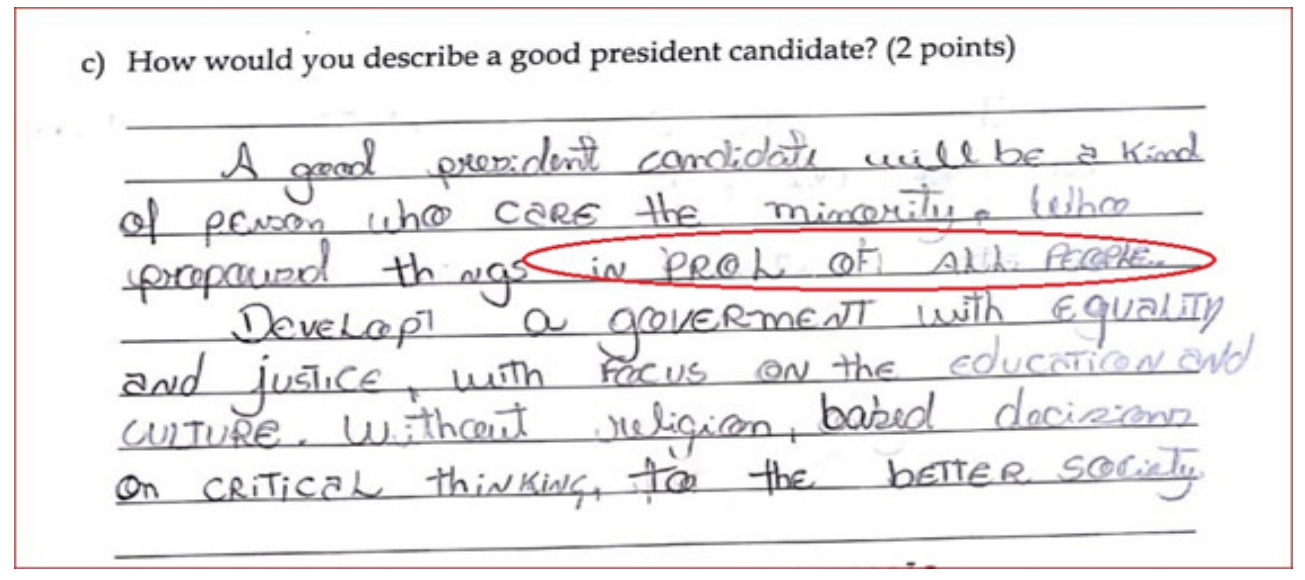

Fonte: Dados dos pesquisadores.

Ademais, a forma como Mariana se posiciona, política e ideologicamente, demonstra também princípios preconizados pelos LC e a translinguagem em defesa de uma sociedade mais justa e democrática para todos. A discente defende que para caminharmos em direção a uma sociedade melhor, precisamos do pensamento crítico, igualdade e justiça, preocupação com grupos minoritários com foco na educação e na cultura sem o envolvimento da religião. Nesse ponto, observamos um repertório linguístico translocal que transita fortemente nos movimentos de esquerda pelo mundo. Vale pontuar o momento histórico em que o Brasil passou pós-impeachment (golpe) da primeira mulher a se tornar presidenta do país e uma acirrada divisão entre os de "esquerda" e os de "direita". Nesse contexto, muitos cidadãos começam a se interessar, como nunca visto no país, por política nacional e internacional e nós, linguistas aplicados, começamos a observar esses repertórios translocais/superdiversos ou opostos a esses transitarem nos mais diversos espaços de práticas situadas de letramentos sociais.

Nos dois exemplos apresentados acima e nos próximos dois exemplos a seguir, fica claro, em consonância com Canagarajah (2011), que "ao focar na atividade proposta [na prova], [sujeitos] multilíngues fazem com que a gramática e o vocabulário se tornem subserviente aos propósitos comunicativos [...] sendo [os multilíngues]mais abertos à possibilidade de uma gramática emergente" (p. 412). Pensar um curso de língua adicional 
na perspectiva translíngue é dar espaço legítimo para que os aprendizes usem uma língua inglesa que dê visibilidade à heterogeneidade cultural e linguística democrática daqueles que estão se apropriando dela para comunicação e interação: os falantes brasileiros. A proposta é, dessa forma, "desaprender" (FABRICIO, 2006) e questionar as propostas de ensino de língua na perspectiva monoglota de foco numa língua padrão e correta.

O exemplo a seguir (cf. Figura 3), produzido por Izadora em 2018 em resposta à seguinte pergunta na prova de Língua Inglesa VI: $O$ cartum acima critica o presidente dos Estados Unidos da América, Donald Trump. Os "verdadeiros americanos" referidos ganham voz, enquanto pessoas de grupos minoritários parecem perder a voz no governo atual. Ultimamente, um dos candidatos a presidente tem sido comparado a ele? Você sabe quem é esse candidato? Como eles são comparáveis?, corrobora a preocupação dos discentes quando buscam formas de comunicação com seu interlocutor, neste caso, a professora Gisele. Quando Izadora diz em língua inglesa: "I totally forgot how to say arma" - canto direito inferior da figura, a discente demonstra sua preocupação em ser entendida, isto é, em produzir os significados que realmente busca, com segurança para defender seu ponto de vista. Assim, ela faz valer recursos retóricos como uma estratégia de inteligibilidade e posicionamento, já que múltiplos recursos de comunicação ampliam suas chances de se fazer compreender e alocar claramente sua voz, seu argumento. Percebemos, portanto, na direção de uma pedagogia translíngue (CANAGARAJAH, 2011, p. 415), que as práticas translíngues estão se desenvolvendo também "de baixo para cima - ground up" numa pedagogia dialógica que tem demonstrado que é possível trabalhar a proficiência translíngue enquanto os alunos desenvolvem e articulam reflexões críticas e dialógicas. 
Figura 3. Izadora 2018. Exemplo 3 de uso da translinguagem

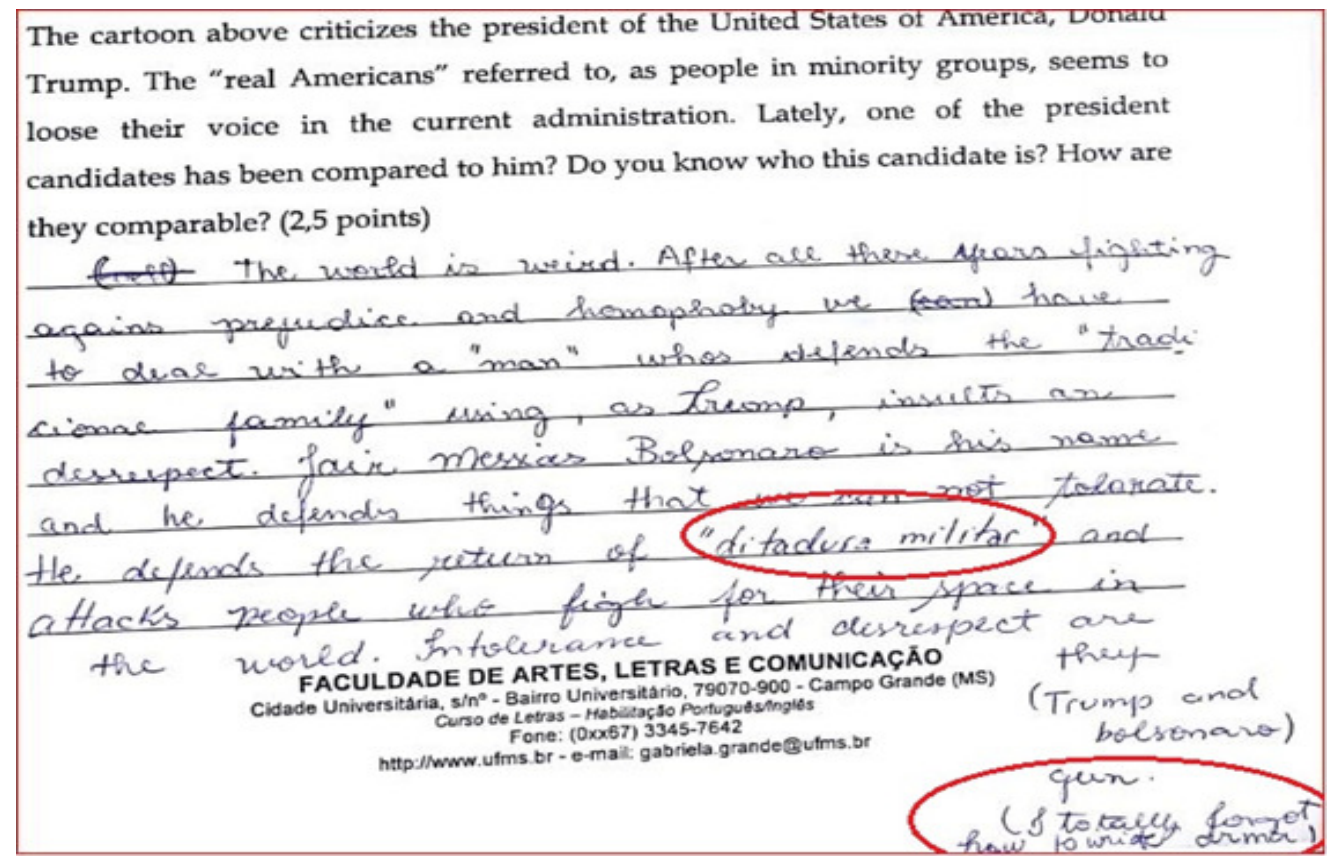

Fonte: Dados dos pesquisadores.

Ainda na Figura 3, observamos uma preocupação da Izadora com os discursos proferidos pelas autoridades de um país. Notamos como os diferentes encontros multissemióticos com os repertórios linguísticos translocais nos afetam diretamente, uma vez pontuado pela discente, o presidente alinhado discursivamente ao presidente dos Estados Unidos, Donald Trump. Há uma preocupação posta pela discente com relação à representação de realidade dada por esses chefes de estado como validação do discurso de ódio, ultranacionalista e ultraconservador da extrema direita.

As respostas analisadas até o momento trazem expressões e posicionamentos pessoais dos discentes que estão, em alguma medida, abertos à apropriação de formas e construções que preencham os valores e os interesses de comunicação das questões, não estando preocupados com o ponto de vista do falante nativo, por exemplo, o que corrobora o estudo de Canagarajah (2011) sobre escrita acadêmica translíngue.

O último exemplo (cf. Figura 4) traz uma forma de expressão da aluna Inês, que demonstra como é relevante para a discente se posicionar ideologicamente e politicamente enquanto uma eleitora que se opõe à direita extremista, materializada pela candidatura do 
então candidato à república Jair Bolsonaro. Independentemente da sua resposta às questões da prova, a aluna faz uma anotação com a utilização de uma hashtag(\#) - recurso utilizado principalmente em redes sociais para alinhamento de ideias ou assuntos - para se posicionar contra a candidatura do referido candidato. Inês utiliza a \# em língua portuguesa de forma translocal, já que a tradução do enunciado em questão não faria sentido em língua inglesa e, por isso, não expressaria o significado exato de seu posicionamento e da representatividade que queria manifestar/marcar.

Figura 4. Inês 2018. Exemplo 1 de uso da translinguagem para "posicionamento ideológico identitário"

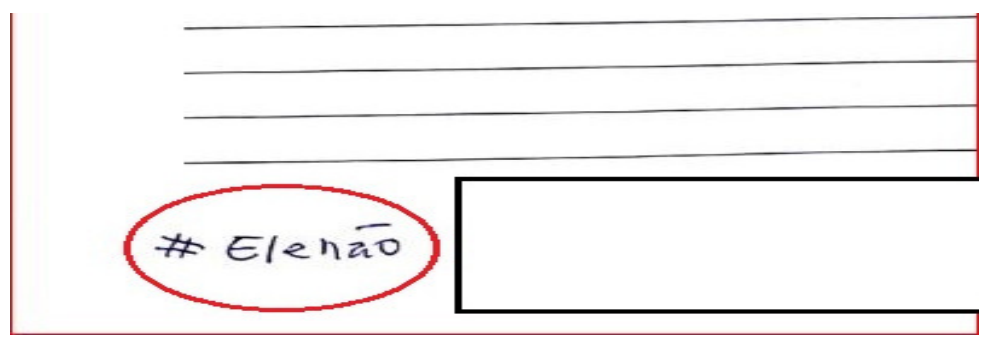

Fonte: Dados dos pesquisadores.

É interessante notar também como essa prática se configura como um posicionamento não só político, mas identitário de Inês. O nível de proficiência da aluna é suficiente para que ela não precisasse utilizar a língua portuguesa em sua prova, mas escolhe fazê-lo para marcar sua identidade política e ideológica e o faz com o uso de uma estratégia transmidiática, já que a \# é um recurso indexador em redes sociais como o Instagram e o Twitter, e multimodal em um texto escrito, muito provavelmente por saber que a professora, Gisele, também acompanhava o movimento nas redes sociais.

\section{CONSIDERAÇÕES FINAIS}

Neste artigo, argumentamos que é necessário desconstruir conceitos monolíngues e tradicionais de ensino língua, levantando a consciência de que esse objeto de ensino é concebido como uma commodity regida por relações de poder/saber monoglotas e colonialistas (LOPES; SILVA, 2018) que devem ser questionadas e relativizadas. Com vistas a dar visibilidade a formas mais fluidas e híbridas de linguagens, não podemos 
esquecer que "translinguagem" não é um método, mas sim um ato político que busca não apenas descrever as práticas linguísticas de falantes de dialetos/variedades marginalizadas (fora do padrão idealizado), mas também analisar as formas como essas práticas produzem significados e se inserem em espaços democráticos legítimos de fala e de comunicação impuros e fronteiriços (FLORES, 2014).

Esta pesquisa se vê também como ativista pela validação de espaços onde as práticas translíngues não sejam consideradas como tentativas ineficazes de comunicação, mas sim reconhecidas e valorizadas como fenômenos linguísticos legítimos de usuários que agem sobre a língua, existem com ela e a constroem pelo uso.

Através dos exemplos analisados, pudemos também apontar que o processo de construção do sujeito bilíngue é complexo, pois o uso real que os sujeitos fazem da "língua adicional" não se encaixa nas premissas tradicionais de línguas enquanto sistemas coesos e independentes. Os resultados mostraram que há coerência linguística e social nos modos como os aprendizes brasileiros no contexto focalizado expressam seus posicionamentos e usam recursos e repertórios linguísticos para se comunicarem em língua inglesa. A professora participante da pesquisa posiciona-se como uma profissional que preza pela construção de processos de ensino-aprendizagem de resistência e de práticas eficazes de letramentos, isto é, processos que propiciem voz e lugar aos diferentes e heterogêneos repertórios linguísticos - ainda que tais repertórios sejam vistos como desvios, pois não "acomodam" estruturas grafocêntricas padronizadas e socialmente valorizadas.

O argumento principal sobre como as práticas translíngues e, portanto, "impuras" dos discentes podem contribuir para apropriação e expansão de seus repertórios linguísticos está justamente na reflexão crítica sobre os fenômenos identificados nas produções escritas. Nosso papel enquanto educadores e estudiosos da linguagem é advogar pela transformação das práticas tradicionais de ensino-aprendizagem, para que os aprendizes possam ter direito ao acesso à variedade dominante e, assim, agir sobre ela,transformando-a e, estrategicamente, incorporando a ela práticas marginalizadas e não dominantes de suas próprias comunidades de fala, ao mesmo tempo em que desenvolvem e ampliam seu repertório e seu domínio da língua. 


\section{REFERÊNCIAS}

ANWARUDDIN, S. M. Translanguaging as Transformative Pedagogy: Towards a Vision of Democratic Education. Revista. Brasileira de Linguística Aplicada [online]. v.18, n.2, p.301-312, 2018.

BLOMMAERT, J. The Sociolinguistics of Globalization. Cambridge: Cambridge University Press, 2010.

BUSCH, B. The linguistic repertoire revisited. Applied linguistics, v.33, n.5, p. 503-523, 2012.

CANAGARAJAH, A. S. Codemeshing in Academic Writing: Identifying Teachable Strategies of Translanguaging. The Modern Language Journal, v.95, n.3, p. 401-417, 2011.

CANAGARAJAH, A. S. (Org.). Literacy as translingual practice: between communities and classrooms. New York: Routledge, 2013.

CASTELLS, M. A sociedade em rede. São Paulo: SP, Editora Paz e Terra, v.1, 2007.

CERVETTI, G.; PARDALES, M. J.; DAMICO, J. S. A Tale of Differences: Comparing the Traditions, Perspectives, and Educational Goals of Critical Reading and Critical Literacy. Reading online, v. 4, n.9, p. 80-90, 2001.

FABRICIO, B. Linguística Aplicada como espaço de desaprendizagem: redescrições em curso. In: MOITA LOPES, L. P. (Org.) Por uma Linguística Aplicada Indisciplinar. São Paulo-SP: Parábola Editorial, p. 45-65, 2006.

FLORES, N. Let's not forget that translanguaging is a political act. Postado online em 19 jul. 2014. Disponível em: <https://educationallinguist.wordpress.com/2014/07/19/lets-notforget-that-translanguaging-is-a-political-act/>. Acesso em: 25 jan. 2020.

GARCÍA, O. Translanguaging in Schools: Subiendo y Bajando, Bajando y Subiendo as Afterword. Journal of Language, Identity \& Education, v. 16, n. 4, p. 256-263, 2017.

KALANTZIS, M; COPE, B. The teacher as designer: Pedagogy in the new media age. $E$ learning and Digital Media, v. 7, n. 3, p. 200-222, 2010.

LEWIS, G.; JONES, B.; BAKER, C. Translanguaging: developing its conceptualisation and contextualisation. Educational Research and Evaluation, v. 18, n. 7, p. 655-670, 2012.

LOPES, A. C.; SILVA, D. do N. Todos nós semos de frontera: ideologias linguísticas e a construção de uma pedagogia translíngue. Linguagem em (Dis)curso - LemD, Tubarão, SC, v. 18, n. 3, p. 695-713, 2018.

MAHER, T. M. Ecos de resistência: políticas linguísticas e línguas minoritárias no Brasil. In: NICOLAIDES, C.; SILVA, K. A.; TÍLIO, R.; ROCHA, C. H. (Orgs.). Política e 
políticas linguísticas. Campinas, SP: Pontes Editores, p. 117-133, 2013.

MAKONI, S.; MEINHOF, U. Linguística Aplicada na África: Desconstruindo a noção de "língua". In: MOITA LOPES, L. P. (Org.) Por uma Linguística Aplicada Indisciplinar. São Paulo: Parábola, p. 191-213, 2006.

MONTE MÓR, W. Crítica e Letramentos Críticos: reflexões preliminares. In: ROCHA, C. H.; MACIEL, R. F. (Orgs.) Língua estrangeira e formação cidadã: por entre discursos e práticas. $1^{a}$ ed. Campinas: Pontes Editores, v. 1, p. 31-59, 2013.

PENNYCOOK, A. Global Englishes and transcultural flows. London: Routledge, 2007.

POZA, L. Translanguaging: Definitions, Implications, and Further Needs in Burgeoning Inquiry. Berkeley Review of Education, v. 6, 2017. Disponível em: <https://escholarship.org/uc/item/8k26h2tp>. Acesso em: 26 jan. 2020.

RAJAGOPALAN, K. A geopolítica da língua inglesa e seus reflexos no Brasil: por uma política prudente e propositiva. In: LACOSTE, Y.; RAJAGOPALAN, K. (Orgs.). A geopolítica do inglês. São Paulo-SP: Parábola Editorial, p.135-159, 2005.

REIS, M. O.; GRANDE, G. C. A translinguagem como ferramenta de aprendizagem e identidade na escrita acadêmica. Papéis, v. 21, n. 41, p. 129-150, 2018.

ROCHA, C. H.; MACIEL, R. F.; MORGAN, B. Critical perspectives in language education and literacies: discussing key concepts. Revista de Letras Norte@mentos, v. 10, n. 23, p. 64-79, 2017.

ROJO, R.; MOURA, E. (Orgs.). Multiletramentos na escola. 1.ed. São Paulo-SP: Parábola Editorial, 2012.

SANTAELLA, L. A ecologia pluralista da comunicação: conectividade, mobilidade, ubiquidade. São Paulo-SP: Editora Paulus, 2010.

SANTOS, R. R. P; IFA, S. O letramento crítico e o ensino de inglês: reflexões sobre a prática do professor em formação continuada. The ESPecialist, v. 34, n. 1, p. 1-23, 2013.

SCHLATTER, M; GARCEZ, P M. Línguas adicionais (espanhol e inglês). Referências curriculares do Estado do Rio Grande do Sul: linguagem, códigos e suas tecnologias. Porto Alegre: Secretaria de Estado da Educação, Departamento Pedagógico, v. 1, p. 127$172,2009$.

TANZI NETO, A.; OLIVEIRA, G. A. Translocalidade, Repertórios e Indexicalidade: Efeitos constitutivos do discurso contemporâneo em espaços digitais superdiversos. INTERCÂMBIO (PUCSP), v. XXXVII, p. 46-68, 2018.

THE NEW LONDON GROUP. A pedagogy of multiliteracies: Designing social futures. Harvard Educational Review, v. 66, n. 1, p. 60-93, 1996. 
TURNER, M.; LIN, A. M. Y. Translanguaging and named languages: productive tension and desire. International Journal of Bilingual Education and Bilingualism, v. 23, n.4, p.423-433, 2017.

VERTOVEC, S. Super-diversity and its implications. Ethnic and racial studies, v. 30, n. 6, p. 1024-1054, 2007.

WENGER, E. Communities of practice: Learning, meaning and identity. New York: Cambridge University Press, 1998.

Recebido em: 29 jan. 2020.

Aceito em: 10 abr. 2020. 